\title{
ROMA 1619. RETRATOS DE LA NACIÓN ESPAÑOLA EN LA GALERÍA DE OTTAVIO LEONI*
}

\author{
Cloe Cavero de Carondelet ${ }^{1}$ \\ Ludwig-Maximilians-Universität München \\ Yuri Primarosa ${ }^{2}$ \\ Sapienza Università di Roma
}

\begin{abstract}
A través de la reconstrucción de las circunstancias en las que Francisco Chacón y otros españoles fueron retratados por Ottavio Leoni en la corte papal, este artículo profundiza en las relaciones artísticas entre Roma y la monarquía española.

Palabras clave: Ottavio Leoni; Toledo; Roma; Luis Tristán; Cardenal Zapata; Cardenal Sandoval; Francisco Chacón; Conde de Casarrubios del Monte.
\end{abstract}

ROME 1619. PORTRAITS OF THE SPANISH NATION IN OTTAVIO LEONI'S GALLERY

Through the reconstruction of the circumstances under which Ottavio Leoni portrayed Francisco Chacón and other Spaniards at the papal court, this article explores the artistic connections between Rome and the Spanish monarchy.

Key words: Ottavio Leoni; Toledo; Rome; Luis Tristán; Cardinal Zapata; Cardinal Sandoval; Francisco Chacón; Count of Casarrubios del Monte.

Cómo citar este artículo / Citation: Cavero de Carondelet, Cloe / Primarosa, Yuri (2017): "Roma 1619. Retratos de la nación española en la galería de Ottavio Leoni”. En: Archivo Español de Arte, vol. 90, núm. 360, Madrid, pp. 383-392. doi: 10.3989/aearte.2017.25

Dixe que en los perfiles consistía la verdadera imitación de los retratos, es decir que, sin debuxo ne se pueden conseguir [...]. Izo también retratos en debuxo el gran Leonardo de Vinchi, Federico Zucaro, Enrique Golzio, el Caballero Josefino [d'Arpino], pero quien ha hecho más estudio en Roma ha sido el Paduano, no perdonando a ninguna persona puesta en dignidad que no debuxase de lápiz, en papel azul, con su realce, con que adornaba su obrador y por ellos los pintaba de colores después ${ }^{3}$.

* Esta colaboración nace durante el encuentro Geografías del Barroco, organizado por el Museo del Prado y celebrado en la Escuela Española de Historia y Arqueología en Roma en mayo de 2016. A los participantes, instituciones organizadoras y, especialmente, a Andrés Úbeda de los Cobos, nuestra gratitud por hacerlo posible. La investigación conducente a este artículo ha sido posible gracias al programa "Salvador de Madariaga" del Ministerio de Educación, Cultura y Deporte, y al Dottorato di ricerca in Storia dell'arte de la Sapienza Università di Roma.

1 cloe.cavero@1mu.de / ORCID iD: http://orcid.org/0000-0003-0389-8226.

2 yuri.primarosa@hotmail.it / ORCID iD: http://orcid.org/0000-0003-4414-2193.

3 Pacheco, 1990: 526-527. 


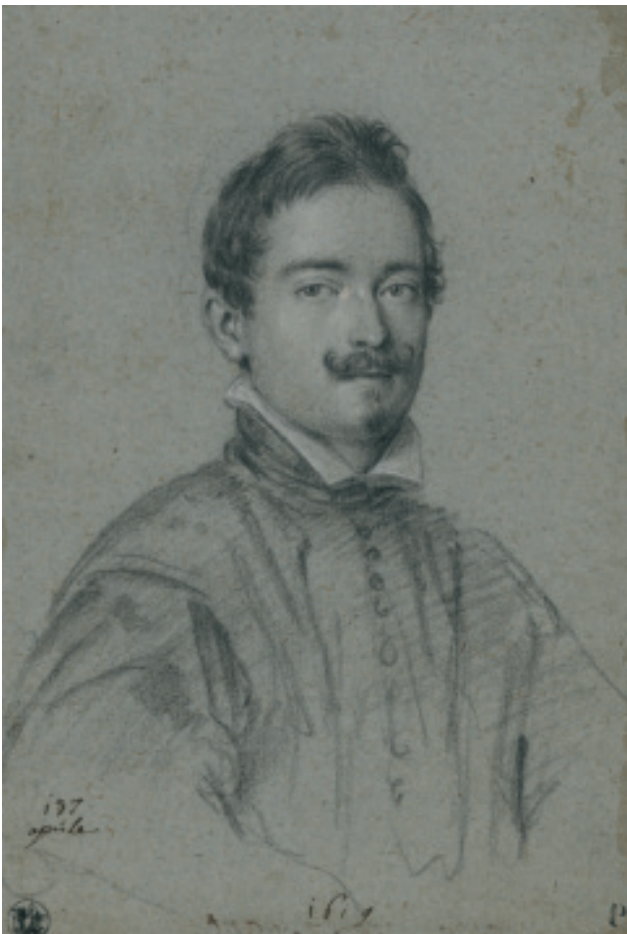

Fig. 1. Ottavio Leoni, Retrato de Gaspar Veri, abril 1619. Lápiz negro y tiza blanca sobre papel azul, 222x150 mm, Berlín, Staatliche Museen, Kupferstichkabinett, KdZ 17080.
Con estas palabras, llenas de entusiasmo y admiración, el pintor sevillano Francisco Pacheco reconocía la primacía en el género del retrato dibujado al artista romano Ottavio Leoni (15781630), conocido entonces como "il Padovanino" debido a los orígenes de su padre Ludovico en la terraferma veneciana. La "fatica virtuosa" de este dibujante había atravesado los confines de la península italiana, probablemente gracias a las noticias llegadas de la mano de Diego Velázquez - discípulo y yerno de Pacheco- a la vuelta de su primer viaje a Roma. Aunque la repentina desaparición de Ottavio, sobrevenida el 1 de septiembre de 1630 "con dispiacere di tutti" 4 , hace más difícil un posible encuentro entre ambos, es muy posible que Velázquez pudiese llegar a admirar algunos de los varios centenares de folios azules en los que Ottavio fijaría los rostros de los hombres ilustres de su tiempo. Durante el transcurso de su larga carrera, Ottavio Leoni retrataría no solo a "sommi pontefici, principi, cardinali, signori titolati”, sino también a gentilhombres, artistas, amigos, familiares, músicos y valent'huomini de diversas procedencias y "d'ogni altra qualità purché famosi fussero, sì religiosi come secolari" 5 .

Pese a que dentro de la producción de retratos dibujados del Padovano se ha identificado a un importante número de españoles ${ }^{6}$, su fortuna entre la comunidad española residente o de paso en Roma no sido objeto de estudio hasta el momento. Y sin embargo, entre abril y julio de 1619 el artista retrataría a cinco súbditos de la monarquía católica estantes en esta ciudad, relacionados a través de redes clientelares coincidentes dentro de la curia romana. Este grupo, único en la amplia galleria cartacea recogida por Leoni, parece desplegarse alrededor de una circunstancia concreta que, como veremos, determinaría intensos intercambios políticos y diplomáticos entre España y la Santa Sede durante ese verano.

En abril de 1619 Ottavio inmortalizó a Gaspar Veri (fig. 1), un joven clérigo de unos veinticinco años, de aires seductores, con una pequeña mosca y los bigotes vueltos hacia arriba ${ }^{7}$. Nacido en Mallorca hacia 1595 e hijo de "Don Raymundi de Veri", Gaspar se había mudado recientemente a Roma, en donde residía en el vicolo delle Colonnelle, en los alrededores de las iglesias de la Magdalena y de Santa Maria in Aquiro, y donde fallecería en noviembre de $1635^{9}$.

Baglione, 1995: 322

5 Baglione, 1995: 321.

${ }^{6}$ Véase una relación detallada en Primarosa, en prensa.

7 Inscripciones: al recto, autógrafa, "137/ aprile/ 1619”; al verso y “46” y “D[ot]tor Gaspar Virgli Espanol” (verso); sobre el montaje "Dotor Gaspar Virgili Espagol”. Véase Primarosa, 2013: 238-240.

8 Así se advierte en diversos documentos notariales firmados en 1634. Archivio Storico Capitolino (ASC), Archivio Urbano, Sez. I, vol. 520, 1634, f. 35v, 336v. Gaspar era hijo legítimo Don Ramon de Veri y Doña Anna Mas.

9 Archivio Storico del Vicariato di Roma (ASVR), San Lorenzo in Lucina, Libro dei morti, III, 1634-1643, c. 40: "Don Gaspero Verij Maiorchino di età di anni 40 in circa, morì nella Comunione della Santa Madre Ecclesia nella casa dove habbitava al vicolo delle Collonelle doppo di haver riceuto tutti li sacramenti della chiesa, ciouè la Confessione, Comunione et oglio S.to, e la racomandatione del anima dal padre Benedetto Farina Curato, il cui corpo fu sepolto alla chiesa della Madonna di Monserrato a Corte Savella a dì 8 detto [novembre 1635]". 


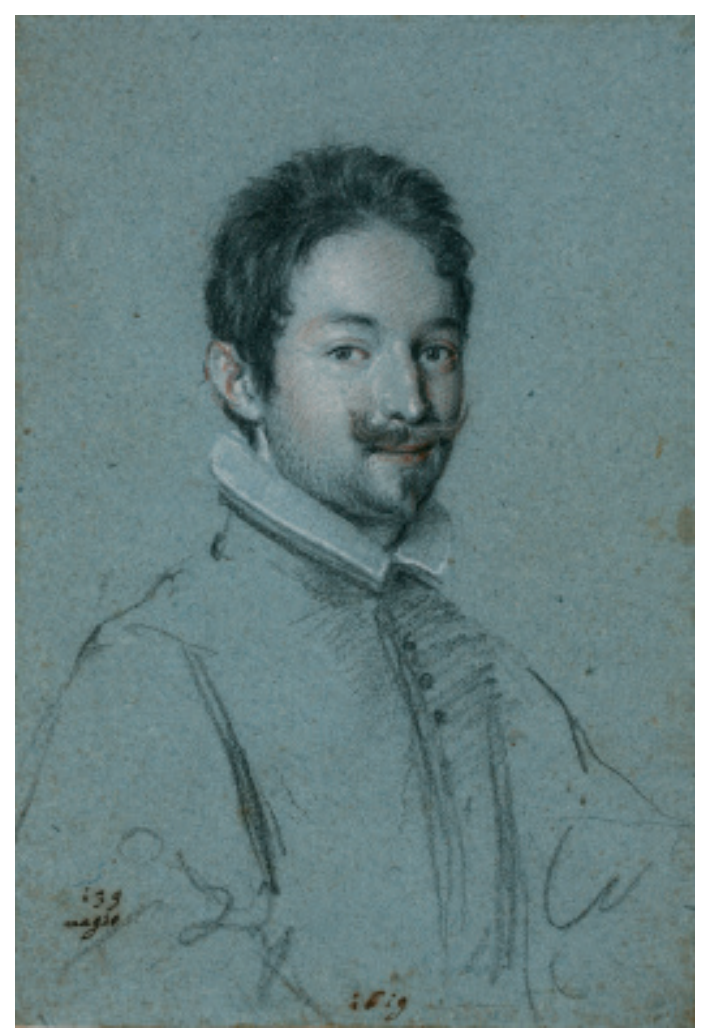

Fig. 2. Ottavio Leoni, Retrato de Francisco Moral, mayo 1619. Lápiz negro y rojo, tiza blanca sobre papel azul, 246×167 mm, Florencia, Accademia Toscana di Scienze e Lettere "La Colombaria", inv. 715

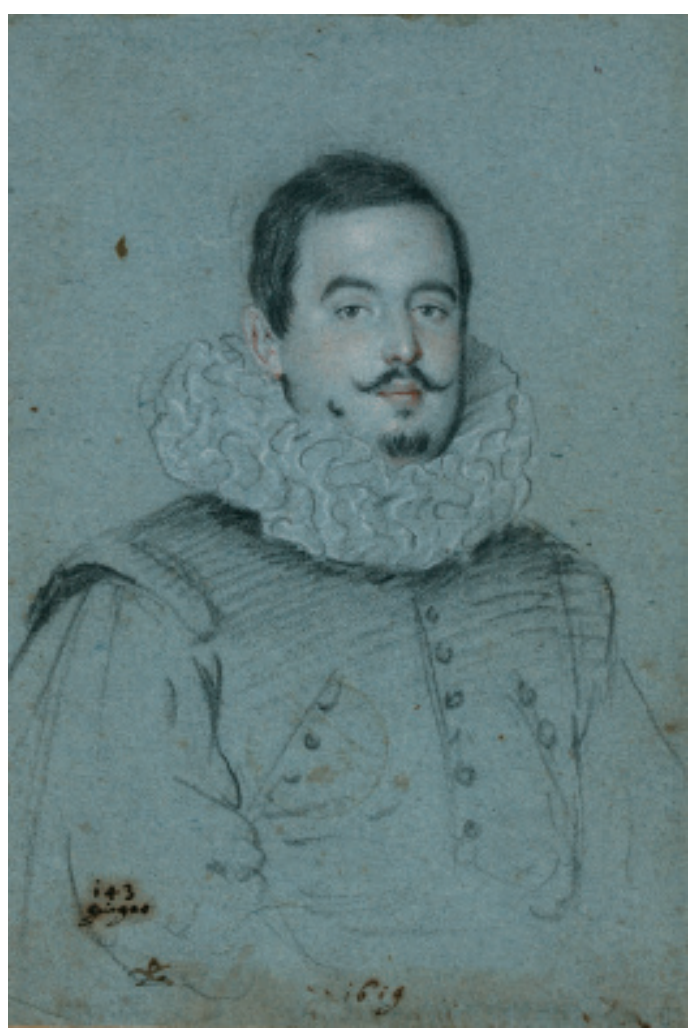

Fig. 3. Ottavio Leoni, Retrato de H. Pimentel, junio 1619. Lápiz negro y rojo, tiza blanca sobre papel azul, 240x167 mm, Florencia, Accademia Toscana di Scienze e Lettere "La Colombaria", inv. 717.

En su última voluntad, firmada un año antes, Gaspar declaraba estar afectado por una "malatia corporal dela qual tem morir" y pedía ser sepultado en la iglesia nacional de la Corona de Aragón, Santa Maria in Montserrato. Además de instituir misas y sufragios por su alma en su localidad de origen, el clérigo declaraba que "me volunta es que se imbie à Mallorca lo meu retrato iuntament ad un quadro de Troya"10. Este último se puede relacionar con las escenas nocturnas de incendios y batallas, muy difusas en las colecciones españolas e italianas de este período, donde destacan los originales de Filippo Napoletano, Paul Brill, Brueghel, Herri met de Bles y Juan de la Corte. Por otra parte, la extraordinaria referencia a un retrato pintado de Gaspar sugiere que el clérigo poseía una versión hecha sobre tela de la efigie dibujada por Leoni. Mediante el envío de este valioso legado a Mallorca, Gaspar deseaba dejar un recuerdo tangible de sí mismo a sus familiares y amigos.

Es posible que Gaspar Veri, miembro establecido de la comunidad ibérica en Roma, fuese el responsable de mediar entre Leoni y los españoles que serían retratados por el artista en las siguientes semanas: el canónigo Francisco Moral, efigiado en el mes de mayo (fig. 2), el señor

\footnotetext{
${ }^{10}$ ASC, Archivio Urbano, Sez. I, vol. 514, c. 694.
} 


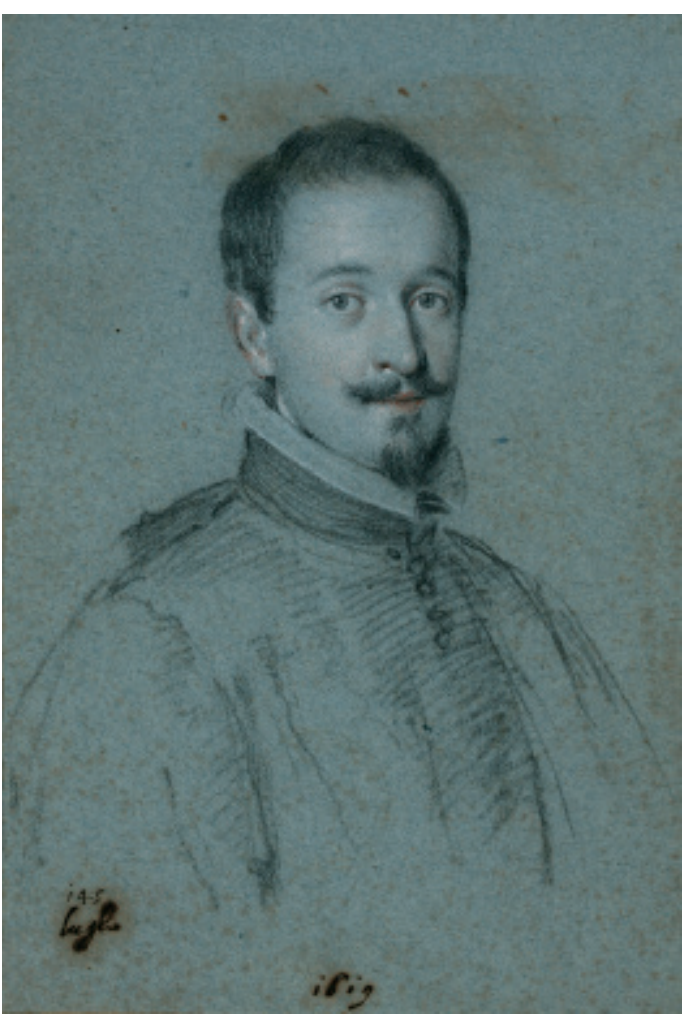

Fig. 4. Ottavio Leoni, Retrato de Francisco Chacón y Rojas (recto), julio 1619. Lápiz negro y rojo, tiza blanca sobre papel azul, 239x167 mm, Florencia, Accademia Toscana di Scienze e Lettere "La Colombaria", inv. 718.

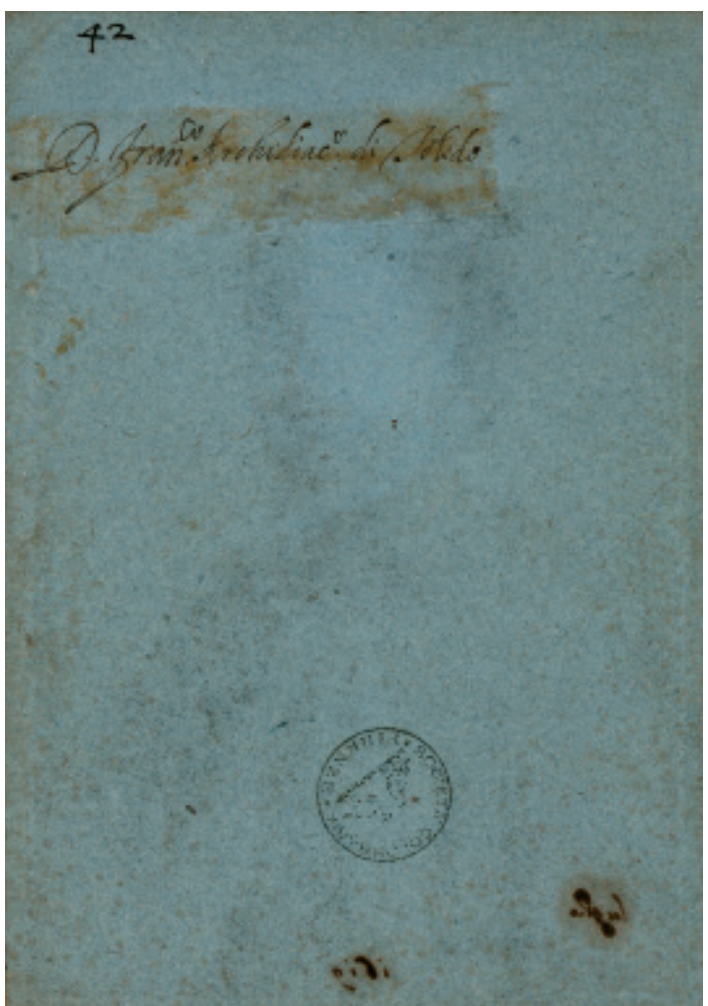

Fig. 5. Ottavio Leoni, Retrato de Francisco Chacón y Rojas (verso), detalle de la inscripción original: "Don Fran[cis]co Archidiac[on]o di Toledo".

Pimentel, inmortalizado en junio (fig. 3), el arcediano Francisco Chacón (fig. 4) y María de Barrionuevo y Montalto, ambos retratados en el mes de julio ${ }^{11}$.

La efigie de Moral es particularmente interesante ya que constituye la manifestación más temprana conocida hasta el momento en la que Leoni realiza un retrato a tres lápices ${ }^{12}$. Gracias a un uso magistral de la tiza y los pasteles pardos, derivados del universo baroccesco, Ottavio logra animar el despejado rostro de Francisco, transmitiendo la serenidad y regocijo de su gesto. Según parece, el artista eligió a este clérigo estante temporalmente en Roma, un personaje secundario y ajeno a sus círculos de amistades y mecenazgo habituales, para experimentar con esta nueva técnica ${ }^{13}$. Ni el sonriente Moral, ni quizá el mismo Leoni podían imaginar que esta efigie sería la que abriría el camino a los más de doscientos retratos que el artista dibujaría a continuación, todos realizados sin solución de continuidad "con tocchi di lapis rosso, che paiono coloriti e di carne tanto sono naturali e vivi" ${ }^{14}$.

11 Maria de Barrionuevo y Montalto era hija de Bernardino (†1611) marqués de Cusano Mutri, y mujer de Giulio de Barrionuevo y Montalto, exponente de la rama española de la familia. Véase Tordella, 2011: 132 y 149. Este retrato también está preservado en el fondo gráfico de la Accademia Colombaria, y proviene de la colección de Alessandro Rivani (1746-1832).

12 Inscripciones: al recto, autógrafa, "139/ magio/ 1619”; al verso “43” y "Don Franc.co Moral”. Tordella, 2011: 88.

${ }_{13}$ Falta el retrato precedente, el número 138 de la serie.

${ }^{14}$ Baglione, 1995: 321. 
Severo y algo altanero se descubre Pimentel (fig. 3), un joven corpulento con un lunar oscuro en el carrillo, de rostro enmarcado por una imponente y rizada lechuguilla ${ }^{15}$. La presencia de una pequeña calavera en la parte inferior del folio, introducida por Leoni antes de 1630, alude a la desaparición prematura del efigiado. Este misterioso gentilhombre, etiquetado como "Signor H. Pimentel", podría pertenecer a la Casa de los condes de Benavente - de continuadas relaciones con Italia-, a la rama de los Pimentel de Prado, o quizá a la de los marqueses de Távara, emparentados con el cardenal Bernardo de Sandoval y por tanto parientes de otro de los retratados, Francisco Chacón (fig. 4) ${ }^{16}$.

Es probable que los tres españoles apenas mencionados participasen, de una manera u otra, en el negocio que llevó a la corte papal a Francisco Gregorio Chacón y Rojas (1585-1626) ${ }^{17}$, inmortalizado por Leoni en el verano de 1619 en el cuarto folio 'a colori' de la serie numerada (fig. 4). Calificado en el verso de la hoja como "Archidiac[on]o di Toledo" (fig. 5), el efigiado ha sido identificado por Piera Giovanna Tordella como Francisco Maldonado. Sin embargo, no cabe duda de que este dibujo representa a Chacón y Rojas, arcediano de Toledo entre 1614 y finales de 1619, y sobrino materno del cardenal Bernardo de Sandoval y Rojas (1546-1618), quien ostentaría la sede primada toledana entre 1599 y diciembre del 1618. Durante los incómodos meses de sede vacante que siguieron el fallecimiento de su tío y protector, y la caída de los Sandovales de la privanza regia, Chacón maduró la decisión de abandonar el estamento eclesiástico. En la primavera de 1619, y probablemente tras reunir a algunas amistades, Chacón partió hacia la Santa Sede para negociar las condiciones de su renuncia. No era una misión sencilla, Chacón quería abandonar la iglesia para poder casarse con la mujer que amaba pero sin perder las rentas derivadas de su arcedianato. En el retrato dibujado por Leoni, Francisco se presenta ante el espectador con sus austeros vestidos clericales, sin elementos accesorios que permitan precisar sus funciones, y revelando a través de la mirada sus esperanzas en alcanzar sus aspiraciones.

\section{"Essendo cosa insolita [...] e di grande difficoltà". La estancia de Francisco Chacón en la corte papal}

El viaje que Francisco Chacón emprendió a Roma en 1619 marcó el fin de la brillante carrera eclesiástica que había mantenido desde su juventud. Francisco Chacón había crecido bajo el amparo del cardenal Sandoval y Rojas, quien desarrollaría un importante mecenazgo artístico durante el reinado de Felipe III ${ }^{18}$. Chacón había sido el sobrino favorito del cardenal Sandoval, quien había recibido las más prestigiosas prebendas de la catedral de Toledo y a quien estaba reservada la sucesión del liderazgo eclesiástico de su linaje. El afecto de Sandoval por su sobrino queda patente en sus testamentos, en donde le reservó su sortija más preciada: un zafiro engarzado en una estructura de oro con el escudo de armas de Sandoval y Rojas y coronado por un capelo cardenalicio que había pertenecido a la familia desde hacía décadas ${ }^{19}$. Menos de un año tras la muerte del prelado, Francisco viajaba a Roma para negociar su salida de la iglesia.

15 Inscripciones: al recto, autógrafa, "143/ giugno/ 1619"; al verso "36" y "S.r H. Pimentello". Véase Tordella, 2011: 133-134 y 148, donde la inscripción al verso está traducida como "S.r N. Pimentello" y el personaje identificado con Diego Pimentel, hombre de armas que moriría en el campo de batalla en Italia en 1624.

16 Los V marqueses de Távara, Antonio Pimentel e Isabel de Moscoso, compraban objetos y cuadros de la almoneda del cardenal Sandoval entre enero y marzo de 1619, en la que participaba Francisco Chacón como ejecutor testamentario del prelado.

17 Inscripciones: al recto, autógrafa, "145/ luglio/ 1619"; al verso "42" y "Don Fran[ces]co Archidiac[on]o di Toledo". Véase Tordella, 2011: 123-134 y 148-149.

18 Cavero de Carondelet, 2016a. Láinez, 1958.

19 Archivo de la Casa Ducal de Medinaceli, Toledo (ADM), Denia-Lerma, 12-12, pliegos 19-20. AHPM, P. 2310, f. $1203 \mathrm{v}, \# 42$. 
Chacón había sido enviado de niño a Pamplona, diócesis donde Sandoval fue obispo entre 1588 y $1595^{20}$, y posteriormente, tras graduarse en Cánones en Salamanca ${ }^{21}$, se trasladó a Toledo para continuar su carrera eclesiástica bajo la protección de su tío ${ }^{22}$. En 1604 ingresaba en el cabildo de Toledo como canónigo, siendo designado capellán mayor del coro y arcediano de Calatrava poco después ${ }^{23}$. En una maniobra irregular, Sandoval elevó a Chacón al arcedianato de Talavera en 1613. Como la elección de esta vacante correspondía tradicionalmente al papa, el nombramiento fue impetrado en la corte de Roma ${ }^{24}$. En mayo de ese año, la corte papal negoció con el cardenal Sandoval, el duque de Lerma y el clérigo Luis de Oviedo para intentar que suspendiese este nombramiento ${ }^{25}$. Tras meses de deliberaciones, la fuerte voluntad del cardenal dio su fruto, y en febrero de 1614 el papa aceptaba el nombramiento de Chacón al arcedianato de Talavera $^{26}$. Sin embargo, la inesperada vacante de la mayor dignidad del cabildo toledano hizo que en abril de 1614 Francisco Chacón fuese nombrado arcediano de Toledo. Este arcedianato conllevaba rentas de más 30.000 ducados anuales, unas rentas muy superiores a muchas rentas episcopales, y ponía a Chacón en una posición propicia para desarrollar actividades de mecenazgo cultura ${ }^{27}$. Su interés por la literatura queda patente en su participación en distintos certámenes poéticos, como el que tenía lugar en Madrid con ocasión de las fiestas de beatificación de Santa Teresa $^{28}$ o el celebrado en Toledo en 1616 con motivo de la traslación de la imagen de la Virgen del Sagrario ${ }^{29}$. El interés de Chacón por la literatura se reafirma con la adquisición que hizo en 1615 de una imponente biblioteca de más de 400 volúmenes $^{30}$. Son pocas las certezas que tenemos sobre sus gustos artísticos y materiales. Si colaboró junto a su tío en alguna de las muchas comisiones artísticas realizadas por éste, nada sabemos. Como albacea del cardenal Sandoval, Francisco fue uno de los responsables en llevar a cabo la almoneda de sus bienes y la realización de las obras pías ${ }^{31}$. De esa almoneda, Francisco y su hermano Bernardo adquirieron "quatro antepuertas de tapiceria", "una botella de ambar con brocal de ebano", "una garrafilla de christal", tapetes "de la yndia" y otros objetos menores ${ }^{32}$.

El 21 de abril de 1619, la secretaría de la corte papal escribía al nuncio en Madrid sobre la complicada petición de Francisco Chacón: quería renunciar al arcedianato de Toledo para casarse, reservándose una pensión anual de 14.000 escudos $^{33}$. Probablemente ese mismo mes de abril, Chacón emprendió el viaje a Roma ${ }^{34}$. El 15 de julio se informaba al nuncio de su llegada, y se mencionaba que Chacón ya había mantenido una primera reunión con Paolo V Borghese ${ }^{35}$. Es en este contexto donde se enmarca la serena y grave expresión con la que Ottavio Leoni inmortalizó al joven Chacón. La siguiente reunión del arcediano toledano con el pontífice no tardaría, y antes de finales de agosto Chacón pudo exponerle su deseo de casarse con Francisca Enríquez de Ribera, hija de Perafán de Ribera y de la condesa de la Torre Inés Enríquez y Sandoval, quien había sido camarera mayor de la infanta Ana de Austria, actual reina de Francia, y que ahora

\footnotetext{
${ }^{20}$ Archivo Histórico Nacional, Madrid (AHN), Consejos, 36222, s.f.

21 Archivo General de Simancas (AGS), Estado, Legajo 1857, f. 364.

22 Archivo Capitular de Toledo (ACT), Expediente de Limpieza de Sangre n. ${ }^{\circ 94}$, ff. 3-9.

23 ACT, Libro de Actas Capitulares (LAC), 23, ff. 224v, 240v-241v, 274v, 326v. ACT, LAC, 24, f. 249r.

24 AGS, Patronato Eclesiástico (PEC), Legajo 77, s.f. ACT, LAC, 26, f. 224.

25 Archivio Segreto Vaticano (ASV), Segreteria di Stato di Spagna (Spagna), 337, ff. 393r-396r.

${ }_{26}$ Biblioteca Apostolica Vaticana (BAV), Barberiniani Latini (Barb. Lat.), 8571: ff. 53-55, 59. ASV, Spagna, 337 , ff. $420 \mathrm{v}-421 \mathrm{r}, 455 \mathrm{v}-456 \mathrm{r}$ y $462 \mathrm{r}$.

27 ASV, Spagna, 60 B, f. 38r. ACT, LAC, 26, f. 346r-v. Cabrera de Córdoba, 1857: 553.

28 San José, 1615: 13.

${ }^{29}$ Herrera, 1617: 2.

30 Archivo Histórico de Protocolos de Madrid (AHPM), P. 2293, ff. 1039r-1048v y 1068.

31 AHPM, P. 2310, f. 1212, \#102. Transcripción parcial en Láinez, 1958: 225-246.

32 AHPM, P. 2312, ff. 91r-96v.

33 ASV, Spagna, 341, ff. 99v-100r y 105v-106v.

${ }^{34}$ El 5 de abril de 1619 Francisco dió un poder general a su hermano Bernardo, una acción habitual previa a la realización de un viaje largo. AHPM, P. 2312, ff. 91r-96v.

35 ASV, Spagna, 341, ff. 146v-147r.
} 
servía a la princesa Isabel de Borbón. Como Francisca Enríquez había entrado en un convento -probablemente en Santo Domingo el Real de Toledo, donde también habían profesado hermanas y tías suyas-, para hacerse monja, la secretaría papal pedía al nuncio que investigase el asunto en profundidad. En particular, la preocupación radicaba en la sospecha de que hubiese sido Francisco Chacón el responsable de hacerle "mutar pensiero", lo que traería consigo que la hipotética difusión de "la corrispondenza tinuta tra loro" produjera un gran escándalo ${ }^{36}$.

La esperanzada expresión con la que Ottavio Leoni retrató a Francisco Chacón tuvo su recompensa, y en abril de 1622, Chacón aparecía documentado como residente en Madrid, autodenominándose "arcediano que fui de la Santa Iglesia de Toledo" y declarando que tenía 100.000 reales anuales de renta sobre ese arcedianato ${ }^{37}$. Todas las gestiones habían sido un éxito. Chacón ingresaba en la Orden de Santiago poco después, y un año más tarde contraía matrimonio con Francisca Enríquez ${ }^{38}$. En 1624, el matrimonio depositaba un brasero de plata, "una tapiçeria de bruselas de la historia de salomon que tiene nuebe paños grandes y un pequeño" y "otra tapiceria de los dioses de la gentilidad que son diez y ocho paños" como garantía del pago de una deuda contraída

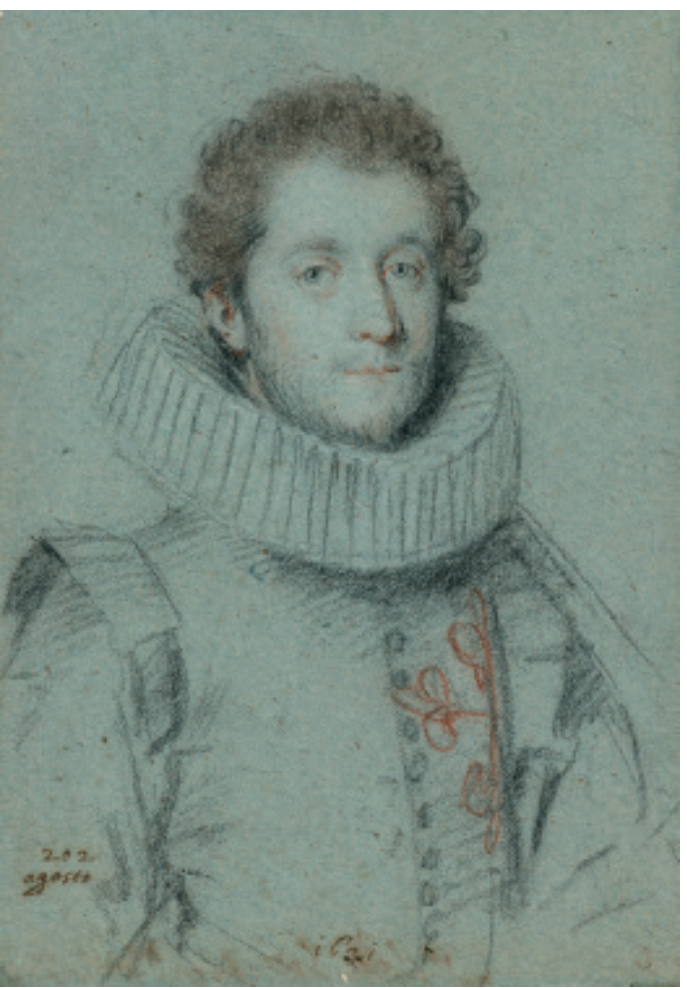

Fig. 6. Ottavio Leoni, Retrato de Gonzalo Chacón y Rojas, II Conde de Casarrubios del Monte, agosto 1621. Lápiz negro y rojo, tiza blanca sobre papel azul, 218x152 mm, Róterdam, Museum Boijmans Van Beuningen, inv. I 126. con los testamentarios del cardenal Sandoval. Sin embargo, éstos decidieron que estos bienes no eran suficiente garantía, y Chacón se vio obligado a sustituirlos por una cadena y arracadas de oro adornadas con más de quinientos diamantes ${ }^{39}$. Un año después, la deuda era pagada y los bienes eran devueltos al matrimonio ${ }^{40}$. El joven Francisco fallecería hacia 1626, truncando la que podría haber sido una interesante actividad como mecenas ${ }^{41}$.

Pero hay más. Dos años después de la misión de Francisco Chacón en la corte romana, en el mes de agosto de 1621, Ottavio retrató al "fr[at]ello dell'Arch[idiaco]no di Toledo" en un folio inédito hoy conservado en Róterdam (fig. 6) ${ }^{42}$. Era éste Gonzalo Chacón y Rojas, caballero del Hábito de Alcántara e hijo del homónimo I Conde de Casarrubios, de quien heredaría el título tras su muerte en noviembre de $1613^{43}$. Es probable que su estancia romana, que sólo conocemos

${ }^{36}$ ASV, Spagna, 341, ff. 160r-161r.

37 AHPM, P. 2326, f. 303.

38 AHN, OM-Caballeros de Santiago, exp. 2315. AHN, OM-Casamiento Santiago, apénd. 156.

39 AHPM, P. 2336, ff. 1136r-1139r.

40 AHPM, P. 2337, ff. 705r-708v.

${ }^{41}$ En 1628, su viuda viajaba a Perú con su segundo marido Luis Jerónimo Fernández de Cabrera y Bobadilla, IV conde de Chinchón y virrey de esa región, dejando atrás un hijo nacido de su matrimonio con Chacón que moriría ese mismo año. Muzquiz, 1945, pp. 30-31.

42 Inscripciones: al recto, autógrafa, "202/ agosto/ 1621"; al verso "S.r [espacio en blanco] Cav.ro fr.llo dell'Arch. no di Toledo".

43 AGS, Cámara de Castilla (CCA), Legajo 1022, f. 48. Véase también un árbol genealógico de los Chacón y Rojas en el último folio de AHN, OM-Caballeros de Santiago, exp. 2315, realizado el 19 de septiembre de 1622. 


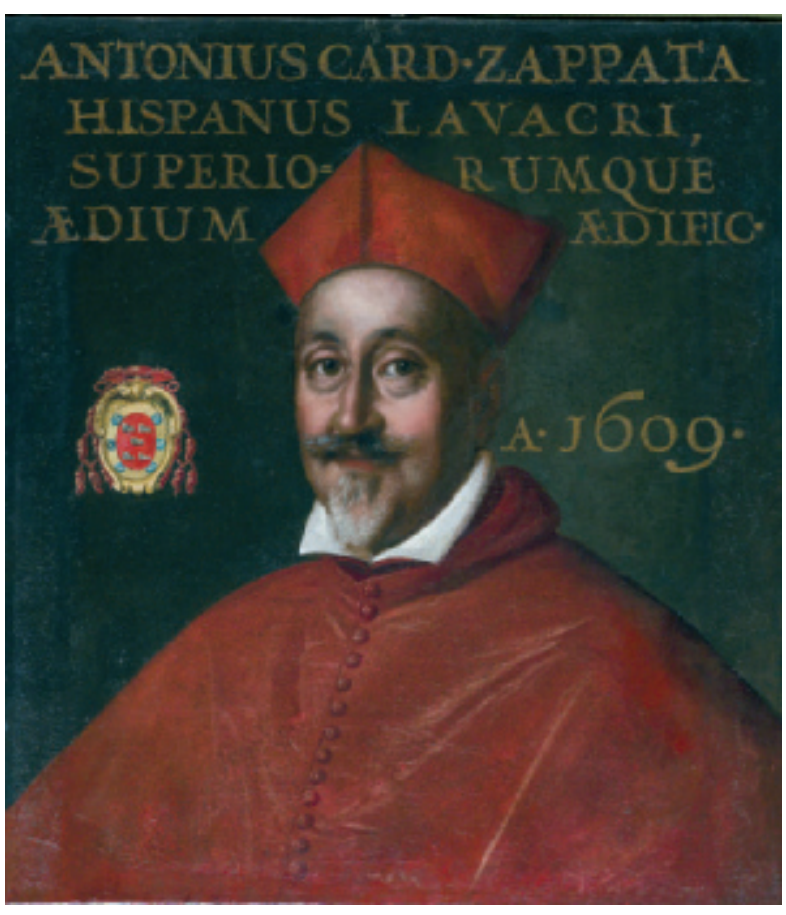

Fig. 7. Ottavio Leoni, Retrato del cardenal Antonio Zapata, 1609-1612 ca. Óleo sobre lienzo, Roma, Conservatorio de Sant'Eufemia.

a través de este dibujo, estuviese relacionada con las complejas negociaciones eclesiásticas de hermano, quien en ese momento estaba preparando su ingreso en la orden de Santiago y sus bodas con Francisca Enríquez de Ribera. Bien parecido, sutilmente melancólico y de rasgos evanescentes como en una efigie al pastel de Federico Barocci, Gonzalo lleva una lechuguilla blanca y un elegante traje oscuro con la cruz de Alcántara recamada sobre el pecho, a la altura del corazón. Leoni lo inmortalizó con una sonrisa contenida y un aire decidido, detenido en una expresión esperanzada de alguna manera similar a la de su hermano.

Los retratos que aquí se presentan constituyen una valiosa evidencia de la importancia que las redes eclesiásticas tuvieron para la circulación artística entre Roma y Castilla a principios del siglo XVII. En la última década, las figuras de embajadores, nuncios y otros agentes diplomáticos se han revelado como fundamentales para comprender el desarrollo de la pintura española ${ }^{44}$. En el caso de Toledo, donde llegaron artistas como Orazio Borgianni y obras de Bartolommeo Cavarozzi y Carlo Saraceni, y en donde trabajaron pintores españoles formados en Roma como Luis Tristán o Juan Bautista Maíno, el papel de las redes eclesiásticas se revela como fundamental ${ }^{45}$. Entre ellos, destaca el importante mecenazgo del cardenal Antonio Zapata, protector de los reinos españoles en Roma y antiguo canónigo toledano, quien sería retratado por Ottavio Leoni para el conservatorio de Sant'Eufemia (fig. 7) ${ }^{46}$. Por otra parte, el mecenazgo de clérigos como Fernando Botinete, Alonso Manrique o Juan Vélez de Valdivieso sería fundamental para la actividad artística de la nación española, especialmente en espacios como las iglesias nacionales y las iglesias titulares de cardenales españoles ${ }^{47}$.

Reconstruir las circunstancias que favorecieron que el joven Pimentel, el Conde de Casarrubios del Monte, y los clérigos Gaspar Veri, Francisco Moral y Francisco Chacón entrasen en

44 Anselmi, 2014. Bernstorff/Kubersky, 2013. Colomer, 2003.

45 Navarrete, 2015. Kientz, 2015. Helmus/Manuth, 2014. Aurigemma, 2013. Ruiz, 2009. Gallo, 1997.

46 Kientz, 2014: 81-91. Primarosa, 2013: 65-66.

47 Cavero, 2016a y 2016b. Kubersky/Koller, 2016. Kazerouni/Kientz, 2015. García Cueto, 2015: 37-53. Marías, 2014. Terzaghi, 2007. 
Fig. 8. Luis Tristán, Retrato del cardenal Bernardo de Sandoval y Rojas, 1619. Óleo sobre tabla,

Toledo, Sala Capitular de la Catedral. (C) Cabildo Primado, Toledo.

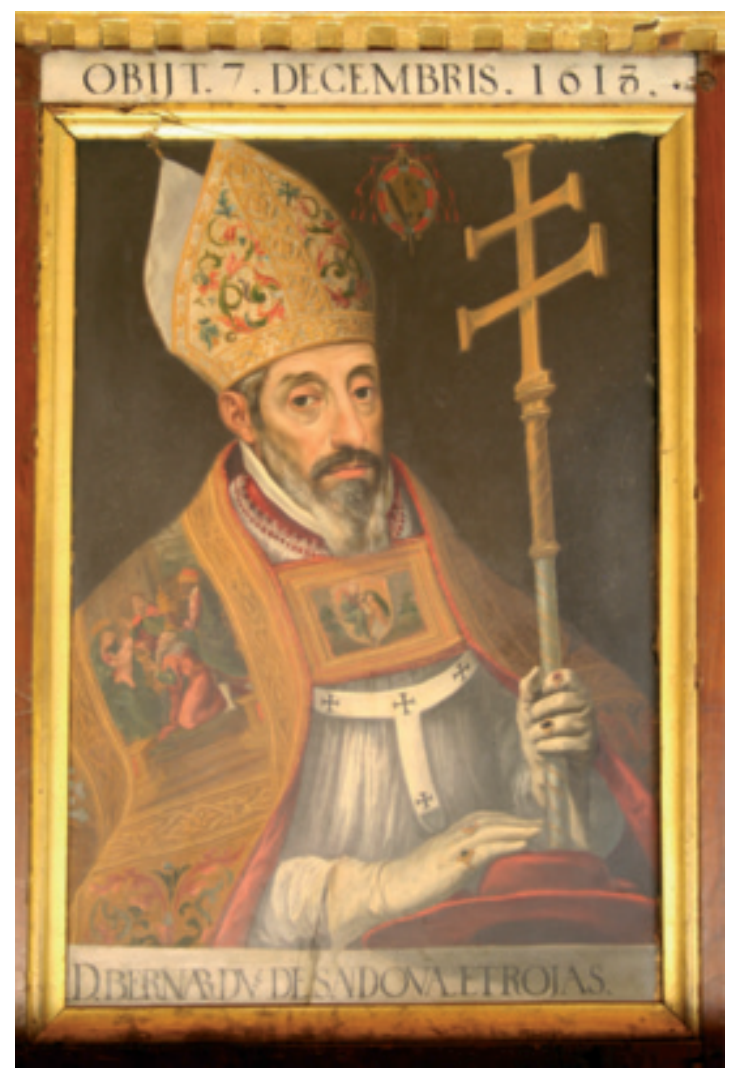

contacto con Ottavio Leoni es complejo. Mientras que parece evidente que Veri y Pimentel estuvieron establecidos de manera permanente en la corte papal, parece ser que tanto Moral como los hermanos Chacón pasaron por Roma sólo brevemente. La inmediatez con la que se produjo el contacto entre Francisco Chacón y Leoni, acaecido escasas semanas tras la llegada del primero a Roma, sugiere la intermediación de un personaje bien relacionado en el escenario romano. Es posible que fuese el canónigo de origen converso Luis de Oviedo, camarero mayor y agente artístico del cardenal Sandoval. Desde 1607 y hasta 1611 Oviedo se trasladó a Roma para negociar la anulación de su expediente de limpieza de sangre y su aceptación en la iglesia de Toledo. $\mathrm{Su}$ convivencia con el pintor Luis Tristán en via Condotti y su importante colección pictórica -poseía lienzos de Tristán, Saraceni, Jusepe de Ribera y una copia de la Madonna dei Pellegrini de Caravaggio- atestiguan el interés artístico de su experiencia romana ${ }^{48}$. Tras su vuelta a Toledo, Oviedo sería fundamental para las comisiones a los pintores Saraceni y Angelo Nardi de la decoración de las fundaciones del cardenal Sandoval, quien sería retratado póstumamente por Tristán en la catedral de Toledo (fig. 8). Además, durante su etapa romana, Luis de Oviedo había colaborado con Giovanni Battista Mucanzio, secretario de la Congregazione dei Riti, en la elaboración de la biografía de Sandoval que había de ser incluida en un compendio dedicado al cardenal nipote en $1615^{49}$. En éste se incluían retratos grabados de cardenales hechos a partir de los dibujos de Ottavio Leoni, que ya habían sido utilizados en un Effigies cardinalium fechado en $1608^{50}$.

\footnotetext{
48 Marías, 2013.

49 Cavero, 2016a.

50 Primarosa, 2014.
} 


\section{BIBLIOGRAFÍA}

Anselmi, Alessandra (ed.) (2014): I rapporti tra Roma e Madrid nei secoli XVI e XVII: arte diplomazia e politica. Roma: Gangemi.

Aurigemma, Maria Giulia (ed.) (2013): Carlo Saraceni, 1579-1620: un veneziano tra Roma e l'Europa. Roma: De Luca.

Baglione, Giovanni (1995): Le vite de' pittori, scultori et architetti dal Pontificato di Gregorio XIII fino a tutto quello d'Urbano VIII nel 1642. Hess, Jacob y Röttgen, Herwarth (eds.). Ciudad del Vaticano: Biblioteca Apostolica Vaticana.

Bernstorff, Marieke von/Kubersky-Piredda, Susanne (eds.) (2013): L'arte del dono: scambi artistici e diplomazia tra Italia e Spagna, 1550-1650. Cinisello Balsamo: Silvana.

Cabrera de Córdoba, Luis (1857): Relaciones de las cosas sucedidas en la corte de España, desde 1599 hasta 1614. Madrid: J. Martín Alegría.

Cavero de Carondelet, Cloe (2016a): Art, Piety and Conflict in Early Modern Spain: The Religious and Artistic Patronage of Cardinal Bernardo de Sandoval between Toledo and Rome (1599-1618). Florencia: European University Institute (tesis doctoral inédita).

Cavero de Carondelet, Cloe (2016b): "Possessing Rome in absentia. The Titular Churches of the Spanish Monarchy in the Early Seventeenth Century". En: Royal Studies Journal, 3, 2: pp. 48-68.

Colomer, José Luis (ed.) (2003): Arte y diplomacia de la monarquía hispánica en el siglo XVII. Madrid: Villaverde.

Gallo, Marco (1997): Orazio Borgianni: Pittore Romano (1574-1616) e Francisco de Castro, Conte di Castro. Roma: UNI.

García Cueto, David (2015): "On the Original Meanings of Gian Lorenzo Bernini’s Anima Beata and Anima Dannata: Nymph and Satyr?". En: Sculpture Journal, 24, 1: pp. 37-53.

Helmus, Liesbeth/Manuth, Volker (eds.) (2014): Utrecht \& le mouvement caravagesque international. París: París Tableau.

Herrera, Pedro de (1617): Descripción de la capilla de N. S. del Sagrario... con las fiestas de su traslación. Madrid: Luis Sánchez.

Kazerouni, Guillaume/ Kientz, Guillaume (eds.) (2015): Ribera à Rome, autour de l'Apostolado. Rennes: Musée des Beaux Arts Rennes.

Kientz, Guillaume (ed.) (2015): Velázquez: catalogue de l'exposition, Paris, Grand Palais, 25 mars-13 juillet 2015. París: RMN-Grand Palais.

Kientz, Guillaume (2014): "Nouveaux courants de la peinture en Espagne: 1600-1620". En: Helmus/Manuth (eds.), pp. 81-92.

Kubersky-Piredda, Susanne/Koller, Alexander (eds.) (2016): Identità e rappresentazione: le chiese nazionali a Roma, 1450-1650. Roma: Campisano.

Láinez, Rafael (1958): Don Bernardo de Sandoval y Rojas, protector de Cervantes (1546-1618). Salamanca: Anaya.

Marías, Fernando (2014): "Pintura, diplomacia y censura en la Cappella Paolina: desde Toledo y Madrid hasta Roma". En: Anselmi, (ed.) pp. 58-86.

Marías, Fernando (2013): "Saraceni e la Spagna”. En: Aurigemma (ed.), pp. 45-56.

Muzquiz de Miguel, José Luis (1945): El conde de Chinchón, virrey del Perú. Madrid: Escuela de Estudios HispanoAmericanos.

Navarrete, Benito (ed.) (2015): El joven Velázquez: a propósito de La educación de la Virgen de Yale. Sevilla: Instituto de la Cultura y las Artes de Sevilla.

Pacheco, Francisco (1990): Arte de la Pintura. Bassegoda i Hugas, Bonaventura (ed.), Madrid: Cátedra.

Primarosa, Yuri (en prensa): Ottavio Leoni (1578-1630), eccellente miniator di ritratti. Catalogo ragionato dell'opera grafica e pittorica. Roma: Ugo Bozzi Editore.

Primarosa, Yuri (2014): "Fermare il modello in posa con la matita, il bulino, il pennello. Il cardinale Erminio Valenti nei ritratti di Ottavio Leoni”. En: Bollettino della Deputazione di Storia Patria per l'Umbria, CXI, II, pp. 963-978.

Primarosa, Yuri (2013): "Ottavio Leoni portraitiste de Paul V et du Collège des cardinaux Borghèse”. En: Solinas, Francesco (ed.), Ottavio Leoni (1578-1630): les portraits de Berlin. Roma: De Luca, pp. 55-71 y fichas catalográficas en pp. 238-240.

Ruiz, Leticia (ed.) (2009): Juan Bautista Maíno, 1581-1649. Madrid: Museo Nacional del Prado.

San José, Diego de (1615): Compendio de las solemnes fiestas que en toda España se hicieron en la beatificación de N.B.M. Teresa de Jesús. Madrid: Alonso Martín.

Terzaghi, Maria Cristina (2007): Caravaggio, Annibale Carracci, Guido Reni tra le ricevute del Banco Herrera \& Costa. Roma: L'Erma di Bretschneider.

Tordella, Piera Giovanna (2011): Ottavio Leoni e la ritrattistica a disegno protobarocca. Florencia: Leo S. Olschki.

Fecha de recepción: 4-VII-2016

Fecha de aceptación: 2-II-2017 